\title{
Preoperative hypoalbuminemia and anemia as predictors of transfusion in radical nephrectomy for renal cell carcinoma: a retrospective study
}

Kyungmi Kim, Hyungseok Seo, Ji-Hyun Chin, Hyo-Jung Son, Jai-Hyun Hwang and Young-Kug Kim*

\begin{abstract}
Background: The only curative therapy for renal cell carcinoma is the complete removal of malignant tissue. Surgical bleeding during radical nephrectomy may require blood transfusion. Blood transfusion, however, is associated with postoperative morbidity and mortality. This study investigated predictive factors of transfusion requirement in patients undergoing radical nephrectomy, as well as the effects of transfusion on postoperative outcomes.
\end{abstract}

Methods: This study retrospectively enrolled 526 patients who underwent open radical nephrectomy for renal cell carcinoma between 2010 and 2012. Univariate and multivariate logistic regression analyses were used to determine independent predictive factors of a requirement for packed red blood cell (PRBC) transfusion. Postoperative outcomes included an admission to the intensive care unit (ICU) and lengths of ICU and hospital stay.

Results: Of the 526 patients, 93 (17.7\%) required PRBC transfusion, with these patients requiring a mean 5.5 units. Preoperative hypoalbuminemia (serum albumin $<3.5 \mathrm{~g} / \mathrm{dL}$ ) was observed in $75(14.3 \%)$ patients, and preoperative anemia (hemoglobin $<12.0 \mathrm{~g} / \mathrm{dL}$ ) in 121 (23.0\%). Multivariate logistic regression analysis showed that preoperative hypoalbuminemia, preoperative anemia, and a high cancer stage were independent factors significantly associated with PRBC transfusion in open radical nephrectomy. The transfused group had higher incidence of ICU admission and longer lengths of ICU and hospital stay than the non-transfused group.

Conclusions: Preoperative hypoalbuminemia and anemia are important predictors of PRBC transfusion during radical nephrectomy for renal cell carcinoma. Furthermore, transfusion is associated with poor postoperative outcomes.

Keywords: Anemia, Hypoalbuminemia, Radical nephrectomy, Renal cell carcinoma, Transfusion

\section{Background}

Renal cell carcinoma, the most common form of kidney cancer, initially has an asymptomatic clinical course; thus, $25-30 \%$ of patients present with metastatic disease at the time of diagnosis [1]. However, the increased utilization of abdominal radiologic imaging has led to an ever-growing proportion of incidentally discovered renal tumors. Since radical nephrectomy for localized renal masses results in excellent long-term prognosis, there have been steady advances in surgical techniques that

\footnotetext{
* Correspondence: kyk@amc.seoul.kr

Department of Anesthesiology and Pain Medicine, Asan Medical Center, University of Ulsan College of Medicine, 88 Olympic-ro 43-gil, Songpa-gu, Seoul 138-736, South Korea
}

have dramatically improved the ability to safely remove these tumors [2]. However, despite improvements in preoperative diagnostic modalities, anesthetic management, and perioperative care, the morbidity and mortality rates remain high, primarily due to hemorrhage and pulmonary embolism [3]. Therefore, it is important to identify factors predicting hemorrhage and subsequent blood transfusion, which may be associated with postoperative outcomes.

Most previous reports on nephrectomy have focused on the occurrence of postoperative complications [4-6]; however, information about factors predictive of intraoperative blood transfusion is limited. Therefore, the present study examined factors predictive of a requirement for packed red blood cell (PRBC) transfusion in 
patients undergoing open radical nephrectomy for renal cell carcinoma, as well as the effects of PRBC transfusion on postoperative outcomes after open radical nephrectomy.

\section{Methods \\ Subjects}

This study retrospectively reviewed the electronic medical records and laboratory results of all patients who underwent open radical nephrectomy for renal cell carcinoma at our institution between January 2010 and December 2012. We excluded the patients who underwent open partial nephrectomy, laparoscopic partial/radical nephrectomy or hand assisted laparoscopic surgery. The study protocol was approved by the Institutional Review Board of Asan Medical Center (AMC IRB-2013-0533).

During the study period, 548 patients with suspected kidney cancer underwent open radical nephrectomy. However, 6 patients who did not perform preoperative abdominal computed tomography (CT) and 4 patients with double primary renal cell carcinoma involving both kidneys were excluded. Furthermore, 12 patients with different pathologic diagnosis; 5 patients with metastatic renal nodule from lung or liver, 5 patients with ureter caner, 1 patient with transitional cell carcinoma in kidney and 1 patient with malignant mixed mullerian tumor, were excluded. Finally, a total of 526 patients were included. Demographic variables included patient age, gender, body mass index, history of hypertension, diabetes or abdominal surgery, coronary artery disease defined as stenosis of one or more coronary arteries with $>50 \%$ occlusion of the vessel lumen, and respiratory disease including chronic obstructive pulmonary disease, history of tuberculosis, asthma or interstitial lung disease. The standard preoperative evaluation at our institution included a clinical examination, chest X-ray, electrocardiography, complete blood counts, liver and renal function tests, coagulation profile, and viral serology. Renal cell carcinomas were staged based on preoperative imaging [7]. Nine patients without formal records of imaging findings did not have their cancer stage because they were diagnosed from other centers before visiting our center. Tumor size was also evaluated by abdominal CT.

\section{Anesthesia}

Following the application of routine hemodynamic monitoring, general anesthesia was induced with thiopental, fentanyl, and rocuronium. After endotracheal intubation, patients were mechanically ventilated and their radial arterial pressure was monitored. Large bore intravenous lines were secured in all patients for fluid management. General anesthesia was maintained with volatile anesthetics, except in 14 patients who were maintained with total intravenous anesthesia, consisting of continuous target controlled infusion of propofol and remifentanil. Fluid management was performed using crystalloids and colloids. During anesthesia, patients were maintained at an arterial systolic blood pressure (SBP) of $\geq 90 \mathrm{mmHg}$ and a hemoglobin concentration of $\geq 8.0 \mathrm{~g} / \mathrm{dL}$.

\section{Surgical procedure}

Patients undergoing open radical nephrectomy with or without tumor thrombectomy were identified and their clinicopathological variables were recorded. Surgical incision was chosen based on an optimal approach to the tumor and vascular control. Open radical nephrectomy was performed in a standard manner by 4 urologists. Tumor thrombectomy was performed in 23 patients with venous thrombi. Five patients with a level IV tumor thrombus adherent to the right atrial wall also underwent cardiopulmonary bypass.

\section{PRBC transfusion criteria and postoperative outcomes}

Intraoperative transfusion was performed in accordance with standard transfusion guidelines [8]. Indications for $\mathrm{PRBC}$ transfusion included an intraoperative hemoglobin concentration $<8 \mathrm{~g} / \mathrm{dL}$. The incidence of intraoperative PRBC transfusion was determined from electronic medical records. Furthermore, creatinine levels which are the highest values within 3 postoperative days, pulmonary complications (such as fever $>37.5{ }^{\circ} \mathrm{C}$ or atelectasis on chest X-ray, dyspnea, respiratory failure, and postoperative hypoxia up until 3 days after surgery) [9] and postoperative outcomes were evaluated. Postoperative outcomes included an admission to the intensive care unit (ICU) and lengths of ICU and hospital stay.

\section{Statistical analysis}

Continuous variables were expressed as the mean \pm standard deviation or number (percentage). Categorical data were analyzed using the $\chi^{2}$ or Fisher's exact tests. Univariate logistic regression analysis was used to identify demographic, preoperative laboratory, and intraoperative factors significantly associated with PRBC transfusion requirement. Variables with a $\mathrm{P}$ value $<0.05$ in univariate analysis were included in the multivariate logistic regression analysis to determine independent factors predictive of PRBC transfusion requirement. A P value $<0.05$ was considered statistically significant. All statistical analyses were performed using SPSS 21.0 (SPSS Inc., Chicago, IL, USA).

\section{Results}

The demographic characteristics, preoperative laboratory findings, and intraoperative variables of the 526 patients are shown Table 1. During open radical nephrectomy, 93 (17.7 \%) patients received PRBC transfusions, with each receiving a mean 5.5 units of PRBCs. Preoperative hypoalbuminemia (serum albumin $<3.5 \mathrm{~g} / \mathrm{dL}$ ) was observed 
Table 1 Characteristics, preoperative laboratory values, and intraoperative variables of patients who were and were not transfused with PRBC during radical nephrectomy

\begin{tabular}{|c|c|c|c|}
\hline & Non-transfused group $(n=433)$ & Transfused group $(n=93)$ & $P$ value \\
\hline Age (years) & $55.3 \pm 12.8$ & $57.6 \pm 12.7$ & 0.121 \\
\hline Gender (male/female) & 277 (64.0\%) / 156 (36.0 \%) & 66 (70.9 \%) / 27 (29.1%) & 0.199 \\
\hline Body mass index $\left(\mathrm{kg} / \mathrm{m}^{2}\right)$ & $24.6 \pm 3.4$ & $23.6 \pm 3.5$ & 0.011 \\
\hline Hypertension & $176(40.6 \%)$ & 37 (39.8 \%) & 0.878 \\
\hline Diabetes mellitus & $68(15.7 \%)$ & $17(18.3 \%)$ & 0.540 \\
\hline Coronary artery disease* & $19(4.4 \%)$ & $7(7.5 \%)$ & 0.196 \\
\hline Respiratory disease $^{\dagger}$ & $25(5.8 \%)$ & $9(9.7 \%)$ & 0.167 \\
\hline History of abdominal operation & $98(22.6 \%)$ & $17(18.3 \%)$ & 0.408 \\
\hline \multicolumn{4}{|l|}{ Preoperative laboratory values } \\
\hline Albumin (g/dL) & $4.1 \pm 0.5$ & $3.6 \pm 0.7$ & $<0.001$ \\
\hline Albumin $<3.5 \mathrm{~g} / \mathrm{dL}$ & $36(8.3 \%)$ & $39(41.9 \%)$ & $<0.001$ \\
\hline Hemoglobin (g/dL) & $13.5 \pm 1.9$ & $11.6 \pm 2.2$ & 0.009 \\
\hline Hemoglobin <12.0 g/dL & $72(16.6 \%)$ & 49 (52.7 \%) & $<0.001$ \\
\hline Prothrombin time (INR) & $0.99 \pm 0.08$ & $1.04 \pm 0.10$ & $<0.001$ \\
\hline Platelet $\left(\times 10^{9} / \mathrm{L}\right)$ & $253.0 \pm 78.1$ & $293.8 \pm 129.2$ & 0.004 \\
\hline Creatinine (mg/dL) & $1.3 \pm 2.0$ & $1.4 \pm 2.3$ & 0.965 \\
\hline Uric acid (mg/dL) & $5.3 \pm 1.5$ & $5.3 \pm 1.6$ & 0.258 \\
\hline Crystalloid infused (mL) & $1757.6 \pm 760.4$ & $3897.3 \pm 2758.5$ & $<0.001$ \\
\hline Colloid infused (mL) & $158.2 \pm 268$ & $1145.2 \pm 861.9$ & $<0.001$ \\
\hline Operative time (min) & $193.4 \pm 57.7$ & $332.5 \pm 171$ & $<0.001$ \\
\hline Cancer stage $^{\ddagger}$ & & & $<0.001$ \\
\hline । & 239 (96.0 \%) & $10(4.0 \%)$ & \\
\hline$\|$ & 67 (82.7 \%) & $14(17.3 \%)$ & \\
\hline III & $85(74.6 \%)$ & $29(25.4 \%)$ & \\
\hline IV & 38 (52.1\%) & 35 (47.9\%) & \\
\hline Urologist & & & 0.570 \\
\hline A & $154(85.6 \%)$ & $26(14.4 \%)$ & \\
\hline B & $115(80.4 \%)$ & 28 (19.6\%) & \\
\hline C & 73 (80.2 \%) & 18 (19.8\%) & \\
\hline D & 91 (81.3 \%) & 21 (18.8 \%) & \\
\hline
\end{tabular}

Data are expressed as the mean \pm standard deviation or number (percentage). ${ }^{*}$ Stenosis of one or more coronary arteries with occlusion of more than $50 \%$ of the vessel lumen. ${ }^{\dagger}$ Chronic obstructive pulmonary disease, history of tuberculosis, asthma or interstitial lung disease. ${ }^{\ddagger}$ Based on preoperative imaging [7], except for nine patients without formal records of imaging findings. PRBC packed red blood cell; INR international normalized ratio

in $75(14.3 \%)$ patients and preoperative anemia (hemoglobin $<12.0 \mathrm{~g} / \mathrm{dL})$ in $121(23.0 \%)$.

Comparisons between the 93 patients who required PRBC transfusions and the 433 who did not revealed no significant differences in demographic characteristics, except for body mass index (Table 1). However, preoperative serum albumin (Fig. 1) and hemoglobin (Fig. 2) concentrations were significantly lower in the transfused group than in the non-transfused group.

Univariate logistic regression analysis showed that body mass index, preoperative hypoalbuminemia, preoperative anemia, prothrombin time, platelet count, and cancer stage were significantly related to PRBC transfusion (Table 2).
Multivariate logistic regression analysis showed that preoperative hypoalbuminemia, preoperative anemia, and more advanced cancer stage were independent factors significantly associated with PRBC transfusion in patients undergoing open radical nephrectomy for renal cell carcinoma (Table 2).

There was no significant difference in postoperative creatinine levels between non-transfused and transfused groups $(1.62 \pm 1.90 \mathrm{mg} / \mathrm{dL}$ vs. $1.80 \pm 2.47 \mathrm{mg} / \mathrm{dL}, P=$ 0.507). However, the incidence of pulmonary complications was significantly higher for the transfused group than for the non-transfused group (32.3\% vs. 16.4\%, $\mathrm{P}<0.001)$. The rate of ICU admission was significantly 


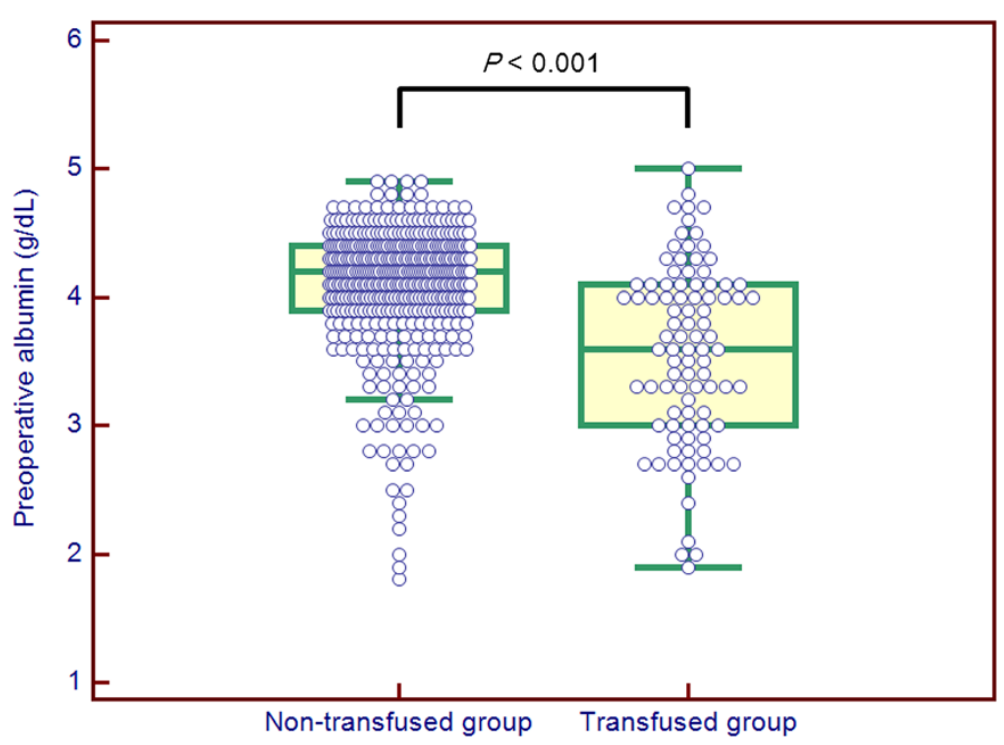

Fig. 1 Box-and-Whisker plots of preoperative albumin levels in patients who were (transfused group) or were not (non-transfused group) transfused with PRBCs. Note that the preoperative albumin level was significantly lower in the transfused group than in the non-transfused group. PRBC: packed red blood cell

higher and the lengths of ICU and hospital stay significantly longer for the transfused group than for the non-transfused group (Table 3).

\section{Discussion}

The main finding of this study was that preoperative hypoalbuminemia, anemia and advanced cancer stage were independent predictors of increased PRBC transfusion requirements and subsequent poor postoperative outcomes in patients undergoing radical nephrectomy for renal cell carcinoma. To the best of our knowledge, this is the first report showing that preoperative hypoalbuminemia and anemia are important predictors of PRBC transfusion requirement in this group of patients.

Renal cell carcinoma accounts for $2 \%$ to $3 \%$ of malignancies in adults, as well as being the third most frequent and the most lethal form of genitourinary cancer $[1,10]$. The only curative therapeutic strategy is the complete removal of malignant renal tissue [3]. Clavien-Dindo complications of grade II or higher have been recorded in

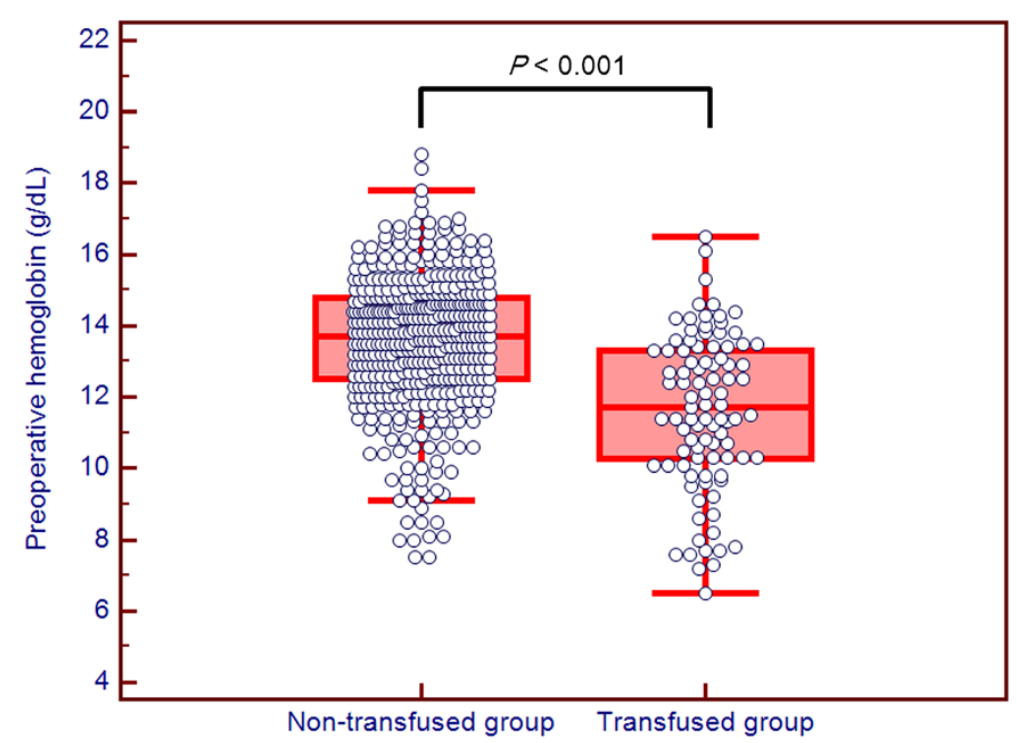

Fig. 2 Box-and-Whisker plots of preoperative hemoglobin levels in patients who were (transfused group) or were not (non-transfused group) transfused with PRBCs. Note that the preoperative hemoglobin level was significantly lower in the transfused group than in the non-transfused group. PRBC: packed red blood cell 
Table 2 Logistic regression analyses of factors independently predicting PRBC transfusion during radical nephrectomy

\begin{tabular}{|c|c|c|c|c|}
\hline \multirow[t]{2}{*}{ Variables } & \multicolumn{2}{|l|}{ Univariate analysis } & \multicolumn{2}{|l|}{ Multivariate analysis } \\
\hline & Odds ratio $(95 \% \mathrm{Cl})$ & $P$ value & Odds ratio $(95 \% \mathrm{Cl})$ & $P$ value \\
\hline Body mass index & $0.919(0.859-0.982)$ & 0.013 & $1.014(0.927-1.109)$ & 0.764 \\
\hline Hypertension & $0.965(0.611-1.524)$ & 0.878 & & \\
\hline Diabetes mellitus & $1.201(0.668-2.158)$ & 0.541 & & \\
\hline Coronary artery disease $^{*}$ & $1.769(0.721-4.339)$ & 0.213 & & \\
\hline Respiratory disease $^{\dagger}$ & $1.749(0.788-3.881)$ & 0.170 & & \\
\hline History of abdominal operation & $0.765(0.432-1.355)$ & 0.358 & & \\
\hline Hypoalbuminemia & $7.965(4.665-13.596)$ & $<0.001$ & $3.687(1.758-7.736)$ & 0.001 \\
\hline Anemia & $5.584(3.458-9.017)$ & $<0.001$ & $3.110(1.635-5.918)$ & 0.001 \\
\hline Prothrombin time & $754.009(62.390-9112.557)$ & $<0.001$ & $2.358(0.083-67.249)$ & 0.616 \\
\hline Platelet & $1.004(1.002-1.007)$ & $<0.001$ & $1.000(0.997-1.003)$ & 0.985 \\
\hline \multicolumn{5}{|l|}{ Cancer stage $e^{\neq}$} \\
\hline । & 1.00 & & 1.00 & \\
\hline$\|$ & $4.994(2.123-11.749)$ & $<0.001$ & $4.822(1.950-11.920)$ & 0.001 \\
\hline III & $8.154(3.813-17.439)$ & $<0.001$ & $9.431(4.210-21.125)$ & $<0.001$ \\
\hline IV & $22.013(10.074-48.103)$ & $<0.001$ & $15.752(6.835-36.302)$ & $<0.001$ \\
\hline
\end{tabular}

"Stenosis of one or more coronary arteries with occlusion of more than $50 \%$ of the vessel lumen. ${ }^{\dagger}$ Chronic obstructive pulmonary disease, history of tuberculosis, asthma and interstitial lung disease. ${ }^{\ddagger}$ Based on preoperative imaging [7]. PRBC, packed red blood cells

$14.2 \%$ of patients undergoing radical nephrectomy, including a requirement for blood transfusion in $11.1 \%$ [11]. The findings presented here will provide important clinical information about perioperative management that may reduce transfusion-related morbidity in patients undergoing radical nephrectomy.

We found that preoperative hypoalbuminemia was an independent predictor of a requirement for PRBC transfusion during open radical nephrectomy. Serum albumin concentration is not only disease-specific but indirectly reflects the nutritional status of both acutely ill patients in the ICU and chronically ill patients with gastrointestinal tract bleeding [12-14]. Hypoalbuminemia may represent more advanced disease; moreover, because of the lower oncotic pressure may favor a leak of effective intravascular volume into the interstitial space, hypoalbuminemia may induce a hypovolemic state [15]. In patients with hypoalbuminemia and subsequent hypovolemia, the ensuing loss of blood during surgery can further reduce the effective circulating volume [16-18]. Hypoalbuminemic patients with reduced effective circulating volume are therefore

Table 3 Postoperative outcomes of patients who were and were not transfused with PRBC during radical nephrectomy

\begin{tabular}{llll}
\hline & $\begin{array}{l}\text { Non-transfused group } \\
(n=433)\end{array}$ & $\begin{array}{l}\text { Transfused group } \\
(n=93)\end{array}$ & $P$ value \\
\hline ICU admission & $8(1.8 \%)$ & $34(36.6 \%)$ & $<0.001$ \\
ICU stay (day) & $0.06 \pm 0.6$ & $2.1 \pm 8.4$ & $<0.001$ \\
Hospital stay (day) & $8.42 \pm 3.0$ & $16.9 \pm 15.5$ & $<0.001$ \\
\hline
\end{tabular}

Data are expressed as the mean \pm standard deviation or number (percentage). $P R B C$ packed red blood cells, ICU intensive care unit more likely to require PRBC transfusion. Similarly, preoperative comorbid conditions associated with albumin concentrations $<4.0 \mathrm{~g} / \mathrm{dL}$ independently increase the need for blood transfusion [19]. Moreover, several studies using a modified version of the Clavien-Dindo classification system found that hypoalbuminemia was predictive factor of post-nephrectomy complications [20, 21]. Albumin level is also an independent predictor of massive blood transfusion in patients undergoing liver transplantation [22-25].

In agreement with results showing that preoperative anemia is a significant predictor of perioperative blood transfusion in patients undergoing elective surgery [26], the present study showed that preoperative anemia was significantly associated with a need for PRBC transfusion in patients undergoing open radical nephrectomy. These results suggest that patients with a low preoperative hemoglobin concentration reach a threshold for blood transfusion more rapidly than patients with a normal preoperative hemoglobin concentration $[27,28]$.

Blood transfusion has remained a mainstay for the management of severely anemic patients and of patients requiring a rapid increase in hemoglobin concentration [29]. Transfusion itself, however, carries significant risks and is associated with postoperative morbidity and mortality [30]. Similar to previous reports [30-32], we found that the group requiring $\mathrm{PRBC}$ transfusions were more likely to have poor postoperative outcomes, such as increased rate of postoperative ICU admission and longer ICU/hospital stay.

The present study found that advanced cancer stage was a predictor of the requirement of PRBC transfusion. 
Similarly, more advanced clinical $\mathrm{T}$ and $\mathrm{N}$ stages were significantly associated with higher rates of blood transfusion and postoperative complications [33]. Because of the level of tumor thrombus is included in $\mathrm{T}$ staging, it could also influence intraoperative blood loss and subsequent need for blood transfusion during surgery [34].

This study has a possible limitation. The present study was retrospectively designed, so we reviewed medical records for collecting data. However, the important perioperative information for the purpose of the present study is generally well documented.

\section{Conclusion}

In conclusion, this study showed that preoperative hypoalbuminemia and anemia were important predictors of PRBC transfusion in patients undergoing radical nephrectomy for renal cell carcinoma. Moreover, blood transfusions were associated with poor postoperative outcomes. Identifying factors predictive of PRBC transfusion can provide better information about perioperative management, which may reduce the need for blood transfusion and, thus, prevent poor outcomes in patients undergoing radical nephrectomy.

\section{Abbreviations}

CT: Computed tomography; ICU: Intensive care unit; INR: International normalized ratio; PRBC: Packed red blood cell.

\section{Competing interests}

The authors declare that they have no competing interests.

\section{Authors' contributions}

KK carried out data collection, statistical analysis and manuscript writing. HS participated in protocol development and performed data management. JHC and HJS carried out data collection and performed data management. $\mathrm{JHH}$ participated in protocol development and data analysis. YKK conceived of the project development, and participated in its design and coordination and performed manuscript editing. All authors read and approved the final manuscript.

\section{Acknowledgements}

The authors would like to thank Drs. Ji Yeon Kim, Jihion Yu, and Jung-Min Yi for collecting data.

Received: 20 November 2014 Accepted: 13 July 2015

Published online: 21 July 2015

\section{References}

1. Gupta K, Miller JD, Li JZ, Russell MW, Charbonneau C. Epidemiologic and socioeconomic burden of metastatic renal cell carcinoma (mRCC): a literature review. Cancer Treat Rev. 2008;34(3):193-205. doi:10.1016/j.ctrv.2007.12.001.

2. Vaidya A, Ciancio G, Soloway M. Surgical techniques for treating a renal neoplasm invading the inferior vena cava. J Urol. 2003;169(2):435-44. doi:10.1097/01.ju.0000047230.49976.bf.

3. Gonzalez J. Update on surgical management of renal cell carcinoma with venous extension. Curr Urol Rep. 2012;13(1):8-15. doi:10.1007/s11934-011-0222-0.

4. Wheat JC, Roberts WW, Hollenbeck BK, Wolf Jr JS, Weizer AZ. Complications of laparoscopic partial nephrectomy. Urol Oncol. 2013;31(1):57-62. doi:10.1016/j.urolonc.2010.11.003.

5. Lawindy SM, Kurian T, Kim T, Mangar D, Armstrong PA, Alsina AE, et al. Important surgical considerations in the management of renal cell carcinoma (RCC) with inferior vena cava (IVC) tumour thrombus. BJU Int. 2012;110(7):926-39. doi:10.1111/j.1464-410X.2012.11174.x.

6. Tan HJ, Hafez KS, Ye Z, Wei JT, Miller DC. Postoperative complications and long-term survival among patients treated surgically for renal cell carcinoma. J Urol. 2012;187(1):60-6. doi:10.1016/j.juro.2011.09.031.

7. Kidney. In: Edge SB, Byrd DR, Compton CC, Fritz AG, Greene FL, Trotti A, editors, AJCC cancer staging manual. 7th ed. New York, NY: Springer 2010. p. 479-89.

8. American Society of Anesthesiologists Task Force on Perioperative Blood T, Adjuvant T. Practice guidelines for perioperative blood transfusion and adjuvant therapies: an updated report by the American Society of Anesthesiologists Task Force on Perioperative Blood Transfusion and Adjuvant Therapies. Anesthesiology. 2006;105(1):198-208.

9. Canet J, Mazo V. Postoperative pulmonary complications. Minerva Anestesiol. 2010;76(2):138-43.

10. Kim HL, Zisman A, Han KR, Figlin RA, Belldegrun AS. Prognostic significance of venous thrombus in renal cell carcinoma. Are renal vein and inferior vena cava involvement different? J Urol. 2004;171(2 Pt 1):588-91. doi:10.1097/ 01.ju. $0000104672.37029 .4 b$.

11. Henderson JM, Fowler S, Joyce A, Dickinson A, Keeley FX, Baus. Perioperative Outcomes of 6042 Nephrectomies in 2012: Surgeon-reported results in the United Kingdom from the BAUS Nephrectomy Database. BJU international. 2014. doi:10.1111/bju.12770.

12. Saltzman JR, Tabak YP, Hyett BH, Sun X, Travis AC, Johannes RS. A simple risk score accurately predicts in-hospital mortality, length of stay, and cost in acute upper Gl bleeding. Gastrointest Endosc. 2011;74(6):1215-24. doi:10.1016/j.gie.2011.06.024.

13. Hyett BH, Abougergi MS, Charpentier JP, Kumar NL, Brozovic S, Claggett BL, et al. The AIMS65 score compared with the Glasgow-Blatchford score in predicting outcomes in upper Gl bleeding. Gastrointest Endosc. 2013;77(4):551-7. doi:10.1016/j.gie.2012.11.022.

14. Vincent JL, Dubois MJ, Navickis RJ, Wilkes MM. Hypoalbuminemia in acute illness: is there a rationale for intervention? A meta-analysis of cohort studies and controlled trials. Ann Surg. 2003;237(3):319-34. doi:10.1097/01.SLA.0000055547.93484.87.

15. Valdespino-Trejo A, Orea-Tejeda A, Castillo-Martinez L, Keirns-Davis C, Montanez-Orozco A, Ortiz-Suarez G, et al. Low albumin levels and high impedance ratio as risk factors for worsening kidney function during hospitalization of decompensated heart failure patients. Exp Clin Cardiol. 2013;18(2):113-7.

16. Karaahmet F, Coban S, Yuksel I. Gastrointestinal bleeding and transfusion strategies in patients with hypoalbuminemia. Dig Dis Sci. 2014;59(2):493. doi:10.1007/s10620-013-2997-y.

17. Kasuya H, Onda H, Yoneyama T, Sasaki T, Hori T. Bedside monitoring of circulating blood volume after subarachnoid hemorrhage. Stroke. 2003;34(4):956-60. doi:10.1161/01.STR.0000064321.10700.63.

18. Gines P, Cardenas A, Arroyo V, Rodes J. Management of cirrhosis and ascites. N Engl J Med. 2004;350(16):1646-54. doi:10.1056/NEJMra035021.

19. Magovern JA, Sakert T, Benckart DH, Burkholder JA, Liebler GA, Magovern $\mathrm{Sr} \mathrm{GJ}$, et al. A model for predicting transfusion after coronary artery bypass grafting. Ann Thorac Surg. 1996;61(1):27-32. doi:10.1016/00034975(95)00808-X.

20. Dindo D, Demartines N, Clavien PA. Classification of surgical complications: a new proposal with evaluation in a cohort of 6336 patients and results of a survey. Ann Surg. 2004;240(2):205-13.

21. Silberstein JL, Adamy A, Maschino AC, Ehdaie B, Garg T, Favaretto RL, et al. Systematic classification and prediction of complications after nephrectomy in patients with metastatic renal cell carcinoma (RCC). BJU Int. 2012;110(9):1276-82. doi:10.1111/j.1464-410X.2012.11103.X

22. McCluskey SA, Karkouti K, Wijeysundera DN, Kakizawa K, Ghannam M, Hamdy A, et al. Derivation of a risk index for the prediction of massive blood transfusion in liver transplantation. Liver Transpl. 2006;12(11):1584-93. doi:10.1002/lt.20868.

23. Ramos E, Dalmau A, Sabate A, Lama C, Llado L, Figueras J, et al. Intraoperative red blood cell transfusion in liver transplantation: influence on patient outcome, prediction of requirements, and measures to reduce them. Liver Transpl. 2003:9(12):1320-7. doi:10.1016/jts.2003.50204.

24. Cacciarelli TV, Keeffe EB, Moore DH, Burns W, Chuljian P, Busque S, et al. Primary liver transplantation without transfusion of red blood cells. Surgery. 1996;120(4):698-704.

25. Hendriks HG, van der Meer J, Klompmaker IJ, Choudhury N, Hagenaars JA, Porte RJ, et al. Blood loss in orthotopic liver transplantation: a retrospective 
analysis of transfusion requirements and the effects of autotransfusion of cell saver blood in 164 consecutive patients. Blood Coagul Fibrinolysis. 2000;11 Suppl 1:587-93.

26. Goodnough LT, Shander A, Spivak JL, Waters JH, Friedman AJ, Carson JL, et al. Detection, evaluation, and management of anemia in the elective surgical patient. Anesth Analg. 2005;101(6):1858-61. doi:10.1213/ 01.ANE.0000184124.29397.EB.

27. Dunne JR, Malone D, Tracy JK, Gannon C, Napolitano LM. Perioperative anemia: an independent risk factor for infection, mortality, and resource utilization in surgery. J Surg Res. 2002;102(2):237-44. doi:10.1006/ jsre.2001.6330.

28. Shander A, Knight K, Thurer R, Adamson J, Spence R. Prevalence and outcomes of anemia in surgery: a systematic review of the literature. Am J Med. 2004;1 16(Suppl 7A):58S-69. doi:10.1016/j.amjmed.2003.12.013.

29. Shander A, Javidroozi M, Ozawa S, Hare GM. What is really dangerous: anaemia or transfusion? Br J Anaesth. 2011;107 Suppl 1:141-59. doi:10.1093/bja/aer350

30. Shander A. Preoperative anemia and its management. Transfus Apher Sci. 2013. doi:10.1016/j.transci.2013.12.006.

31. Jans O, Jorgensen C, Kehlet H, Johansson PI, Lundbeck Foundation Centre for Fast-track H, Knee Replacement Collaborative G. Role of preoperative anemia for risk of transfusion and postoperative morbidity in fast-track hip and knee arthroplasty. Transfusion. 2014;54(3):717-26. doi:10.1111/trf.12332.

32. Perisanidis C, Dettke M, Papadogeorgakis N, Schoppmann A, Mittlbock M, Kyzas PA, et al. Transfusion of allogenic leukocyte-depleted packed red blood cells is associated with postoperative morbidity in patients undergoing oral and oropharyngeal cancer surgery. Oral Oncol. 2012;48(4):372-8. doi:10.1016/j.oraloncology.2011.11.020.

33. Takagi T, Sugihara T, Yasunaga H, Horiguchi H, Fushimi K, Kondo T, et al. Cytoreductive nephrectomy for metastatic renal cell carcinoma: A population-based analysis of perioperative outcomes according to clinical stage. Int J Urol. 2014. doi:10.1111/iju.12446.

34. Boorjian SA, Sengupta S, Blute ML. Renal cell carcinoma: vena caval involvement. BJU Int. 2007;99(5 Pt B):1239-44. doi:10.1111/j.1464410X.2007.06826.X

\section{Submit your next manuscript to BioMed Central and take full advantage of:}

- Convenient online submission

- Thorough peer review

- No space constraints or color figure charges

- Immediate publication on acceptance

- Inclusion in PubMed, CAS, Scopus and Google Scholar

- Research which is freely available for redistribution 